\title{
VITREOUS CYST WITH RETINITIS PIGMENTOSA.* A NEW SYNDROME?
}

BY

\author{
J. W. WAGENAAR \\ Alkmaar, Netherlands
}

THE clinical picture of a congenital vitreous cyst is highly exceptional. Cassady (1939) collected eighteen cases from the world literature. Unilateral retinitis pigmentosa is an equally infrequent disorder, of which Gordon (1949) was able to gather nineteen pure cases. Chance may play a very particular part, witness the fact that McLean (1933) was able to demonstrate one patient with unilateral retinitis pigmentosa followed by a second with a vitreous cyst. But when both these unusual clinical pictures appear in one patient and a fortiori in the same eye, one is strongly inclined to assume a relationship between these two conditions, either through one disorder being due to the other, or both resulting from the same cause. The following clinical observation may serve as a starting-point for our study.

\section{Case Report}

A 47-year-old woman consulted me on July 3,1946, because of difficulties in reading, which could partly te attributed to an incipient presbyopia. The visual acuity in the right eye could be corrected with an error to $5 / 15$ with $\mathrm{S} \ldots 0.5$, that in the left to $5 / 5$ with $\mathrm{S}: 0.5$. The anterior segment of the right eye showed no changes. In the lower

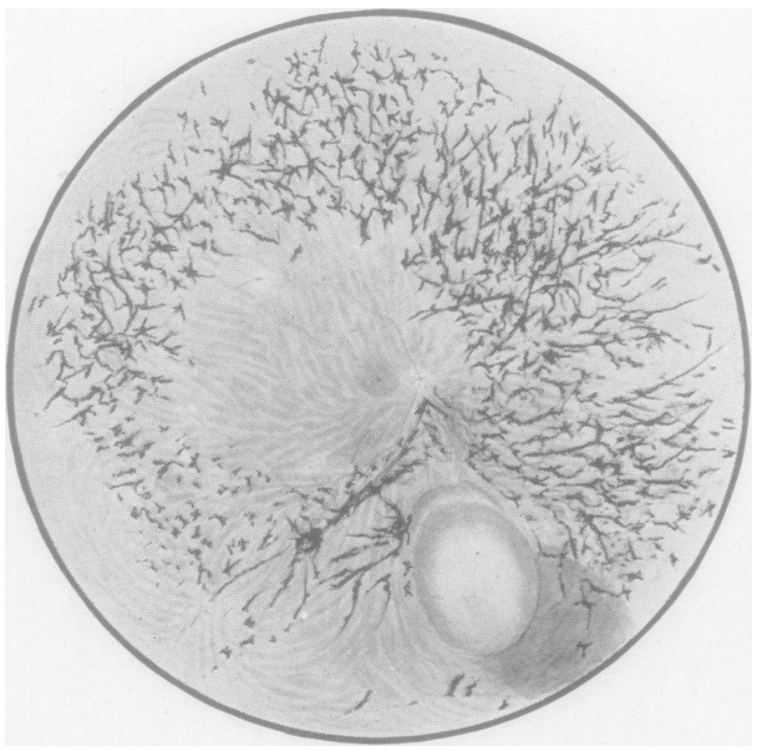

Fig. 1.-Fundus drawing of right eye. nasal region the vitreous contained a semi-transparent, greenish, smooth, pear-shaped cyst, estimated to be about $5 \mathrm{~mm}$. in length, which fluctuated freely in the vitreous, but which, as appeared from its unchangeable position in rest, had at one side a connection with the retina, not to be perceived by the investigator. No independent movements or changes in size could be observed. The right fundus presented the classical ophthalmoscopic findings of retinitis pigmentosa: a pale, slightly yellowish papilla, thin-walled vessels, and the characteristic trabeculate deposits of pigment in the surrounding peripheral areas (Fig. 1).

Except for a small scar due Received for publication April 7, 1952. to choroiditis in the temporal 

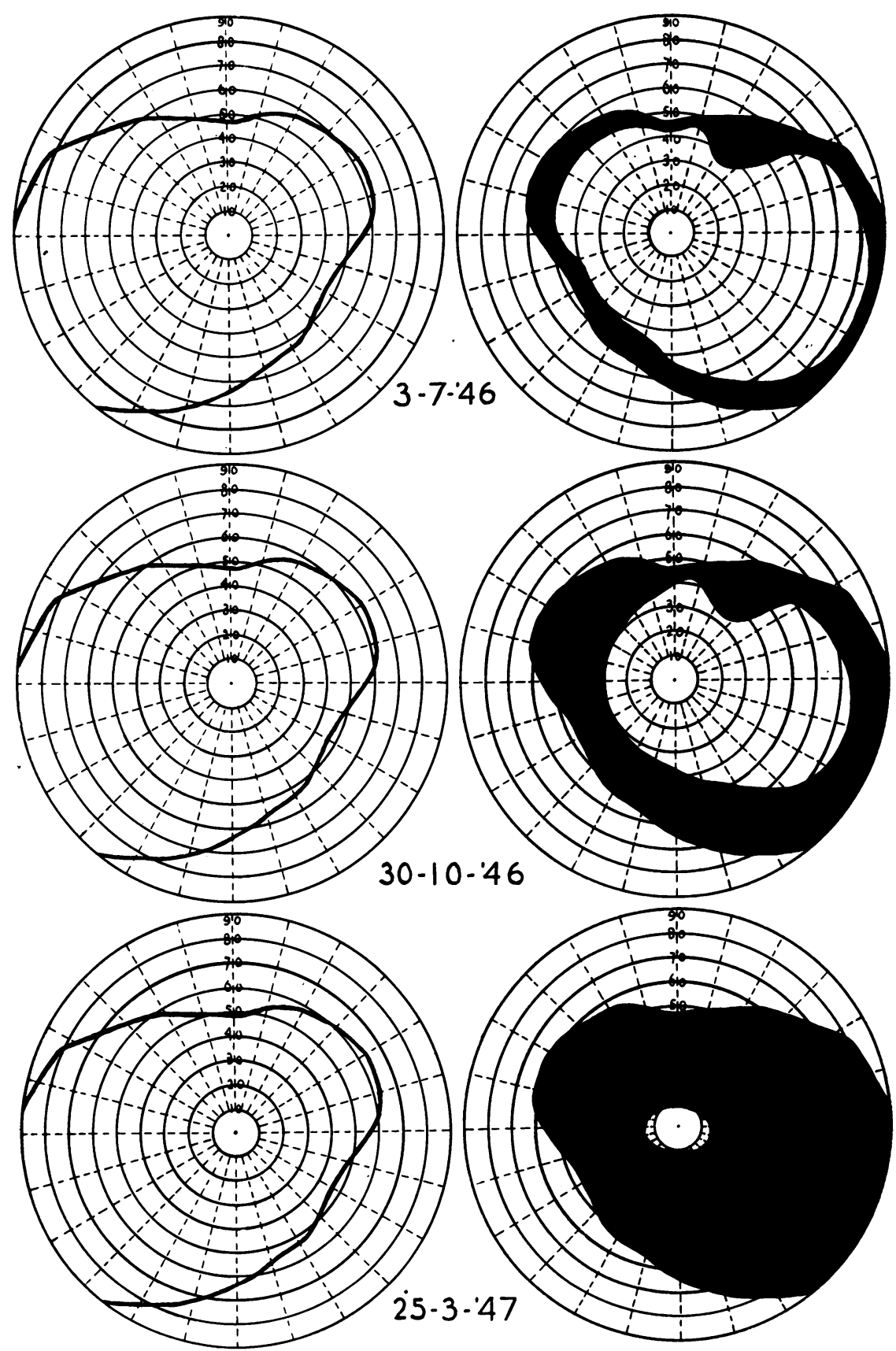

FIG. 2.-Progressive retrenchment of visual field in right eye.

region, the left eye was completely normal. The right field of vision (Fig. 2) showed a slight peripheral constriction, the left being unimpaired. The intra-ocular pressure was normal in both eyes. 


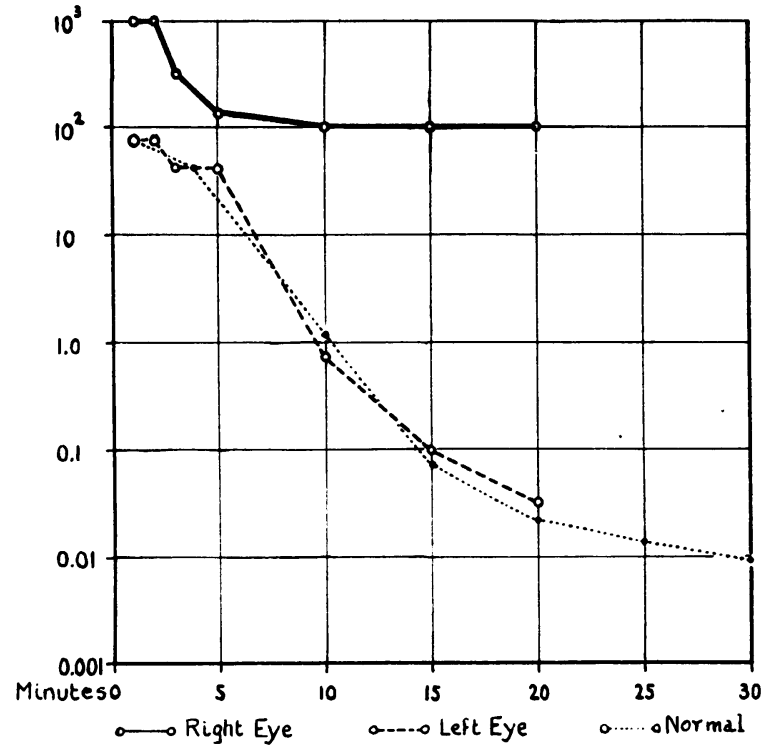

FIG. 3.-Dark-adaptation curves plotted logarithmically.
On October 30, 1946, the visual acuity in the right eye had decreased to $5 / 30$, and the field of vision showed a concentric contraction.

On March 25, 1947, the field of vision had been reduced to $10^{\circ}$. The condition of the left eye had remained unaltered and continued to be normal.

A curve, obtained with Kentgens' apparatus at the Netherlands Ophthalmic Hospital, Utrecht, showed the dark adaptation of the right eye to be considerably impaired, whereas that of the left eye was normal (Fig. 3).

\section{Diagnosis}

In making a diagnosis I first had in mind a parasite, in particular a cysticercus, even a dead specimen. Mac Arthur (1934) has pointed out that, though the host shows a relatively satisfactory tolerance of living cysticerci, a dead specimen may have a markedly irritative effect. Thus the pigmentary degeneration of the eye might be assumed to have been due to the toxins secreted by the dead parasite. This is more or less consistent with the theory of Leber (1916) of the toxic origin of retinitis pigmentosa, with the pigmentary degeneration induced experimentally in laboratory animals by means of injections of sodium iodate into the vitreous (Sorsby, 1941), and with the retinal changes resulting from the presence of a cataractous lens dislocated in the vitreous, as described by Verhoeff (1931). However, this diagnosis was not supported by the haemogram, a maximum proportion of 5 per cent. of eosinophilic cells being found in the course of repeated determinations, so that an eosinophilia could not be said to have occurred. Toulant (1939) has shown that, although eosinophilia is a frequent symptom, its absence is not contradictory to the presence of a cysticercus. Casoni's test was negative in this patient, but this fact does not provide any negative evidence, for Cockburn (1946) reported a case of living cysticercus being found in the vitreous and while there was no doubt as to the diagnosis, eosinophilia was absent and Casoni's test was negative. I am myself, moreover, sceptical of this test, since it was evident that I personally had a markedly positive reaction, although, to my knowledge, I have never housed anything more than harmless ascarides.

The diagnosis was also unsatisfactory in other respects, for the patient's history suggested no starting-point. (The possibility of syphilis could be excluded, as Wassermann's test was negative.) During 5 years of observation the condition remained unchanged.

\section{Similar Cases Previously Reported}

Starting from the assumption that the cyst should not be regarded as parasitic in nature, I found in the literature two reports of cases which showed a striking 
resemblance to my own findings, although the cysts occurred symmetrically in both eyes, and the retinitis pigmentosa was also bilateral:

(1) (Litinsky, 1931). A 24-year-old man presented bilateral, symmetrical, yellow-grey cysts, the size of a pea, localized in the vitreous and invisibly fixed, though relatively movable. The retinae showed the typical changes due to retinitis pigmentosa. The disturbances had been present for 2 years.

(2) (Perera, 1936). A 55-year-old man complaining of a recently impaired dark adaptation, presented two symmetrical cysts in the vitreous, and fundi showing the characteristic changes of retinitis pigmentosa.

Neither author ventures upon a sharply-defined diagnosis, although the parasitic origin of the cysts was rendered extremely unlikely by their bilateral character (cases of undoubted bilateral intra-ocular cysticerci being highly exceptional, of which more later on). Litinsky believed there was no causal relationship between the cysts and the pigmentary degeneration, and according to Perera the retinitis, or at any rate the degenerative tendency, was primary in nature.

In my opinion the case here reported, in which one eye presented the same changes as were encountered by Litinsky and Perera in both eyes, renders it extremely unlikely that the presence of a cyst in the one eye affected with retinitis pigmentosa is merely accidental. The combination of the unusually late development of the (if one insists) "symptomatic" retinitis pigmentosa, the speed with which the field of vision contracted, and, in particular, the unilateral appearance of the disease in the eye which also contained the cyst, practically proves the existence of a causal relationship between the various changes, as was also considered likely by Perera. This case thus constitutes an interesting addition to the reports of Litinsky and Perera.

\section{Cases Combining Other Symptoms}

A closer study of the literature on the simultaneous appearance of a pigmentary degeneration of the retina and cyst-like structures fixed to the retina or pedicled in the vitreous shows that the various examples may be classed as belonging more or less to this clinical picture.

(1) Waardenburg*(1929) reported a 33-year-old woman presenting the following changes:

Right eye, divergent strabismus and strabismus sursumvergens, slightly prominent. Vision limited to the lower temporal perception of hand-movements. Cornea showed no changes. Lens showed a foamy, rosette-shaped, pumice-like, complicated posterior cataract. Vitreous marked by a coarse fibrous structure with white junctions behind the lens. Fundus examination revealed a wax white papilla with fairly narrow arteries, and the entire fundus showed signs of pigmentary degeneration, white stria-like reflections, and streaks running towards certain fundus vessels. Peripheral areas presented typical bone cells, interspersed in places with coarser pigmentations and white atrophic lesions.

In the lower temporal region there was a pear-shaped cystic white lesion, in the vicinity of large pigmented transverse bands and bone cells.

Left eye, showed no particular features, visual acuity 0.8 , corrected with $S-0.5$. According to Waardenburg the possibility of syphilis could be excluded.

(2) During the discussion which followed a lecture delivered by H.W. Scarlett, Hill (1929) reported having examined a middle-aged man, in whom he found a cyst in the vitreous of the right eye, with atrophic papillae and thin-walled retinal arteries in both eyes, the fields of vision showing a concentric contraction.

- I gladly take this opportunity of tendering my best thanks to my colleague P. J. Waardenburg for permission to use his findings in this paper. 
(3) Lacarrère (1930) demonstrated a patient with bilateral cyst-like structures on the nasal halves of the papillae, the width of which was three-quarters that of the papillary diameter, associated with a retinitis pigmentosa. He regarded these cysts as a degeneration product resulting from the retinitis pigmentosa.

(4) Cassady (1939) described a case presenting a vitreous cyst in the right eye and membranes on both papillae; he advanced this theory regarding the possible cause:

The associated prepapillary membrane in the case reported here suggests a remnant of the primitive epithelial papilla of Bergmeister, which forms the sheath of the hyaloid arteries and its branches. The presence of this membrane, the lack of pigment, and the location of the cyst in the centre of the vitreous suggest the primary vitreous as the site and origin of the cyst, as opposed to the theory previously advanced that the cyst probably originated from a degenerative adenomatous cyst of the vitreous processes.

(5) Viewed in this light, it may perhaps be doubted whether the diagnosis of a bilateral intra-ocular cysticercus in the case reported by Weve (1931)* was correct. This was the case of a 17-year-old girl, in whom a small cyst, about half the diameter of the pupil, was encountered in the meridian of 8 o'clock in the right eye, on a white halo, 1 to $1 \frac{1}{2}$ times the diameter of the pupil. A thickened band, leading to the vitreous, was seen to originate from the temporal region of the papilla. The left eye showed signs of optic neuritis. A semi-transparent cyst, twice as large, with a diameter of approximately $3 \mathrm{~mm}$. and completely symmetrical to that in the right eye, was found at about 4 o'clock. Weve observed no retractions, and neither the contents nor portions of the cyst, which was treated with cauterization, could be examined.

In view of the striking resemblance of this case to that reported by Cassady, I think that it may not have been of parasitic origin, but should be classed with those discussed here.

It is difficult to establish criteria by which these cases may be judged, but certain morphological characteristics may be tentatively classified as follows:

\begin{tabular}{|c|c|c|c|c|c|c|c|c|}
\hline \multirow[t]{2}{*}{ Case } & \multirow[t]{2}{*}{ Author } & \multirow[t]{2}{*}{ Date } & \multicolumn{2}{|c|}{$\begin{array}{l}\text { Retinal or Pedicled } \\
\text { Vitreous Cyst }\end{array}$} & \multicolumn{2}{|c|}{$\begin{array}{l}\text { Papillary Cyst or } \\
\text { Prepapillary } \\
\text { Membrane }\end{array}$} & \multicolumn{2}{|c|}{$\begin{array}{c}\text { - Symptomatic } " \\
\text { Retinitis } \\
\text { Pigmentosa }\end{array}$} \\
\hline & & & Right & Left & Right & Left & Right & Left \\
\hline 1 & Litinsky & 1931 & & -. & & & & \\
\hline 2 & Perera & 1936 & -. & & & & & \\
\hline 3 & Wagenaar $\quad .$. & 1948 & & & & & & \\
\hline 4 & Waardenburg & 1929 & - & & & & .... & \\
\hline 5 & $\begin{array}{lll}\text { Hill } & \ldots & \ldots\end{array}$ & 1929 & $\ldots$ & & & & & \\
\hline 6 & Lacarrère & 1929 & & & & & & \\
\hline 7 & Cassady & 1939 & & & & & & \\
\hline 8 & Weve & 1931 & $\ldots$ & $\cdots$ & . & ? & & \\
\hline
\end{tabular}

The retinitis pigmentosa reported above is probably not essentially identical with the well-known, classical form. Since this small series includes two cases of unilateral pigmentary degeneration, it will be better to speak of a "symptomatic" retinitis pigmentosa, bearing in mind the remark of Joseph (1951) that

unilateral retinitis pigmentosa is unrelated to the classical bilateral affection with its clear-cut genetic aspects and characteristic functional disturbances.

Thus it is obvious that the cases of bilateral pigmentary degeneration included

* The reports in the world literature regarding the bilateral appearance of an intra-ocular cysticercus should frequently be considered as doubtful, although a definite diagnosis might be made in exceptional cases. Lech Junior (1949) reports a few bilateral cases in a series of 111 patients with intra-ocular cysticercus. 
above are essentially similar to the unilateral cases and may also be regarded as "symptomatic".

In addition to his own case and those published by Lacarrère and Litinsky, Perera (1936) mentions a case (reported by Vennin, 1910) of a 22-year-old man with a marked degree of myopia and bilateral pedicled cysts in the vitreous, but no impairment of vision or changes in the field of vision. Perera arrived at the following conclusions:

The possible derivations of the cyst are as follows: the structure may arise from the foetal ocular cleft, mesodermal elements of the embryonic vitreous, or the hyaloid apparatus. It may be a dislocated cyst of the ciliary processes, a formed exudate into the vitreous, a product of retinal degeneration (including retinal cysts) or proliferation, or the result of degeneration of a parasitic cyst. The presence of myopia or pigmentary degeneration of the retina or of both these conditions in the four cases of bilateral cyst suggests a congenital degenerative aetiology.

Kraupa (1931) does not believe Litinsky's findings to be so exceptional and claims to have encountered vitreous cysts, mainly bilateral and occasionally associated with a retinitis pigmentosa, while the patients were frequently myopic (6-8D). As he does not supply further data, this material cannot be included in the Table, but it evokes the question whether the myopia should, in a certain sense, be regarded as the equivalent of "symptomatic" retinitis pigmentosa, and thus Perera is justified in including Vennin's case.

\section{A New Syndrome?}

In reporting these data it has been my intention to contribute to a provisional classification of this syndrome, which can gain in clarity only by the addition of new cases. It will not be possible to form a clearer idea of the aetiology, until a larger number of cases is published, for at present the opinions of the various authors are widely divergent.

The possibilities of treatment are outside the scope of this article, and it will not be possible to study them more closely until our knowledge of the aetiology has become clearer. It will then have to be decided whether Gördüren (1950) is correct in saying that:

Cysts in the vitreous, apart from those of parasitic origin, provoke no irritation and therefore require no treatment.

\section{Summary}

A case of unilateral (symptomatic) retinitis pigmentosa, in which a cyst was found in the vitreous of the same eye is described.

By sifting and adding to the cases gathered from the world literature by Perera (1936) an effort has been made to achieve a provisional classification of a clinical picture, the aetiology and therapeutic possibilities of which can gain in clarity only by the addition of new cases.

More cases are probably known to investigators, but have been viewed hitherto from a different angle. I hope to have contributed to a more profound knowledge of a presumably independent syndrome. 


\section{REFERENCES}

Cassady, J. V. (1939). Arch. Ophthal., Chicago, 21, 45.

Cockburn, C. (1946). British Journal of Ophthalmology, 30, 65.

Gordon, D. M. (1949). Amer. J. Ophthal., 32, 1350.

Gördüren, S. (1950). British Journal of Ophthalmology, 34, 749.

Hill, E. (1929). Trans. Amer. ophthal. Soc., 27, 156.

JOSEPH, R. (1951). British Journal of Ophthalmology, 35, 98

Kraupa, E. (1931). Klin. Mbl. Augenheilk., 87, 511.

LACARrère, J. L. (1930). Z Zbl. Ophthal., 22, 776.

LEBER, T. (1916). In Graefe-Saemisch-Hess, "Handbuch der gesamten Augenheilkunde", 2nd ed., bd. VII, teil II, kap. 10A, p. 1076. Engelmann, Leipzig.

LeCH, JNR. (1949). Amer. J. Ophthal., 32, 523.

LitinSKy, G. A. (1931). Klin. Mbl. Augenheilk., 87, 205.

Mac Arthur, W. P. (1934). Trans. Roy. Soc. trop. Med. Hyg., 27, 343.

MClean, A. L. (1933). Amer. J. Ophthal., 16, 51.

Perera, C. A. (1936). Arch. Ophthal., Chicago, 16, 1015.

SORSBY, A. (1941). British Journal of Ophthalmology, 25, 62.

Toulant, P. (1939). In " Traité d'ophtalmologie”, ed. P. Bailliart, C. Couteki, E. Redslob, and E. Velter, vol. 8, p. 717. Masson, Paris.

VENNIN (1910). Lyon méd., 114, 974.

Verhoeff, F. H. (1931). Arch. Ophthal., Chicago, 5, 392.

WAARDENBURG, P. J. (1929). Personal communication.

Weve, H. (1931). Klin. Mbl. Augenheilk., 87, 597. 